\title{
Pemodelan Deteksi Dini Krisis Mata Uang Berdasarkan Indiktor Nilai Tukar Nominal
}

\author{
Adebun ${ }^{1, *}$, Sugiyanto ${ }^{1}$, Isnandar Slamet ${ }^{2}$ \\ 1,2 Program Studi Statistika; Universitas Sebelas Maret; \\ e-mail: ${ }^{1}$ adebun@student.uns.ac.id, ${ }^{1}$ sugiyanto61@ staff.uns.ac.id, ${ }^{2}$ isnandarslamet@ staff.uns.ac.id \\ * Korespondensi: e-mail: adebun@ student.uns.ac.id
}

\section{ARTICLE INFO ABSTRACT}

Keywords:

Crises,

Nominal Exchange Rate, $M S-E G A R C H$

\begin{abstract}
The financial crisis by definition is a situation where several financial assets lose most of their nominal value. The financial crisis experienced by Indonesia in 1997 had a severe impact on the Indonesian economy, so a model was needed to detect this crisis. The financial crisis can be detected using the nominal exchange rate indicator. This study aims to determine the appropriate combination of volatility models and the Markov switching model as a model for detecting financial crises in Indonesia based on nominal exchange rate indicators. The nominal exchange rate indicator taken from 1990 to 2018 is used to build a model for early detection of the financial crisis in Indonesia. The results showed that the combined exponential generalized autoregressive conditional heteroscedasticity and Markov regime switching, MRSEGARCH $(3,1,1)$ volatility models were both used to detect financial crises in Indonesia based on nominal exchange rate indicators.
\end{abstract}

\section{PENDAHULUAN}

Krisis keuangan yang terjadi pertengahan tahun 1997 dimulai ketika nilai mata uang Thailand turun tajam. Gangguan pada sistem keuangan dalam aturan ekonomi dapat menyebabkan krisis mata uang. Krisis mata uang dapat dilihat melalui fluktuasi nilai tukar mata uang sebuah negara. Melihat akibat dari krisis keuangan terhadap penurunan kegiatan ekonomi menyadarkan akan pentingnya membangun sistem deteksi dini sebab akibat krisis tersebut berdampak sangat parah akan perekonomian Indonesia. Indikator nilai tukar mata uang mampu merepresentasikan kinerja perekonomian sebuah negara yang mempunyai fluktuasi dan dapat mengubah kondisi. Perubahan fluktuasi dapat dijelaskan dengan menggunakan model volatilitas. Sementara perubahan kondisi dapat dijelaskan dengan menggunakan model Markov regime switching.

Bollerslev [2] memperkenalkan generalized autoregressive conditional heteroscedasticity (GARCH) untuk memeodelkan data US GNP dari tahun 1948 sampai 1983. Dalam beberapa kasus, model GARCH kurang mampu menjelaskan efek leverage. Chen [3] menjelaskan bahwa efek leverage adalah situasi dimana volatilitas mengalami kabar buruk dan kabar baik secara berkala untuk menghasilkan efek asimetris pada volatilitas sehingga model GARCH dioptimalkan menjadi EGARCH yang mampu mengatasi adanya efek leverage.

Hamilton [5] memperkenalkan model Markov switching (MS) sebagai model data time series yang mengandung perubahan kondisi. Hamilton dan Susmel [6] menggabungkan model MS dan ARCH models untuk menghasilkan model Markov switching autoregressive conditional heteroscedasticity (SWARCH). Mereka mengaplikasikan model SWARCH pada data U.S gross national product (GNP) dari tahun 1952 sampai 1984; model dapat menjelaskan perubahan keadaan yang terjadi dalam data variabel ekonomi U.S GNP. Sugiyanto [8] melalui indikator output real, domestic credit per gross domestic product (GDP), dan ICI mendeteksi krisis keuangan menggunakan kombinasi model volatilitas dan Markov switching. Sugiyanto [9] juga menjelaskan krisis keuangan menggunakan model MS-GARCH melalui indikator perbankan. Penelitian ini membahas model kondisi krisis mata uang yang mungkin terjadi di Indonesia melalui indikator nominal exchange rate menggunakan gabungan model Markov regime switching dan Exponential generalized autoregressive heteroskedasticity. 


\section{METODE PENELITIAN}

Model ARMA(p,0) adalah model AR(p). Model AR(p) dapat ditulis sebagai berikut

$$
\mathrm{r}_{\mathrm{t}}=\phi_{0}+\phi_{1} \mathrm{r}_{\mathrm{t}-1}+\cdots+\phi_{\mathrm{p}} \mathrm{r}_{\mathrm{t}-\mathrm{p}}+\varepsilon_{\mathrm{t}}
$$

dimana $r_{t}$ merupakan $\log$ return pada waktu $t, \varepsilon_{t}$ adalah residu model $A R(p)$, dan $\phi_{0}, \phi_{1}, \ldots, \phi_{p}$ adalah parameter model $\mathrm{AR}(\mathrm{p})$.

Menurut Tsay [12], model GARCH(m,s) dapat ditulis sebagai berikut

$$
\sigma_{\mathrm{t}}^{2}=\alpha_{0}+\alpha_{1} \mathrm{a}_{\mathrm{t}-1}^{2}+\cdots+\alpha_{\mathrm{s}} \mathrm{a}_{\mathrm{t}-\mathrm{s}}^{2}+\beta_{1} \sigma_{\mathrm{t}-1}^{2}+\cdots+\beta_{\mathrm{m}} \sigma_{\mathrm{t}-\mathrm{m}}^{2}=\alpha_{0}+\sum_{\mathrm{i}=0}^{\mathrm{s}} \alpha_{\mathrm{i}} \mathrm{a}_{\mathrm{t}-\mathrm{i}}^{2}+\sum_{\mathrm{j}=0}^{\mathrm{m}} \beta_{\mathrm{j}} \sigma_{\mathrm{t}-\mathrm{j}}^{2} .
$$

Menurut Nelson, model EGARCH dapat ditulis sebagai berikut

$$
\ln \sigma_{j, t}^{2}=\omega_{j}+\beta_{j} \ln \left(\sigma_{j, t-1}^{2}\right)+\gamma \frac{\varepsilon_{t-1}}{\sqrt{\sigma_{t-1}^{2}}}+\alpha\left[\frac{\left|\varepsilon_{t-1}\right|}{\sqrt{\sigma_{t-1}^{2}}}-\sqrt{\frac{2}{\pi}}\right]
$$

Berdasarkan Gray [13], model Markov regime switching generalized autoregressive conditional heteroscedasticity dapat ditulis sebagai berikut

$$
\sigma_{\mathrm{t}, \mathrm{s}_{\mathrm{t}}}^{2}=\alpha_{0, \mathrm{~s}_{\mathrm{t}}}+\sum_{\mathrm{i}=1}^{\mathrm{m}} \alpha_{\mathrm{i}, \mathrm{s}_{\mathrm{t}}} \mathrm{a}_{\mathrm{t}-\mathrm{i}}^{2}+\sum_{\mathrm{j}=1}^{\mathrm{s}} \beta_{\mathrm{j}, \mathrm{s}_{\mathrm{t}}} \sigma_{\mathrm{t}-\mathrm{j}}^{2}
$$

Dengan model Markov regime switching Exponential generalized autoregressive heteroskedasticity adalah,

$$
\ln \sigma_{j, t, s_{t}}^{2}=\omega_{j, s_{t}}+\beta_{j, s_{t}} \ln \left(\sigma_{j, t-1}^{2}\right)+\gamma \frac{\varepsilon_{t-1}}{\sqrt{\sigma_{t-1}^{2}}}+\alpha\left[\frac{\left|\varepsilon_{t-1}\right|}{\sqrt{\sigma_{t-1}^{2}}}-\sqrt{\frac{2}{\pi}}\right]
$$

$\mathrm{s}_{\mathrm{t}}$ menunjukkan variabel random yang tidak teramati memenuhi orde pertama rantai Markov yang dapat mengambil nilai $1,2, \ldots, \mathrm{T}$. variabel $\mathrm{s}_{\mathrm{t}}$ dianggap sebagai keadaan atau regime yang prosesnya dalam tanggal $t$ dan $s_{t}$ mengatur orde pertama rantai Markov. Parameter distribusi bersyarat dan variabel acak yang tidak teramati dengan probabilitas transisis konstan diberikan oleh

$$
P\left[s_{t}=j \mid s_{t-1}=i\right]=p_{i j}, \sum_{j=1}^{T} p_{i j}=1, \text { for } i, j=1,2, \ldots, T .
$$

Dalam notasi matriks, $\mathrm{P}$ dapat didefinisikan oleh

$$
\mathrm{P}=\left(\begin{array}{cccc}
\mathrm{p}_{11} & \mathrm{p}_{21} & \cdots & \mathrm{p}_{\mathrm{T} 1} \\
\mathrm{p}_{12} & \mathrm{p}_{22} & \cdots & \mathrm{p}_{\mathrm{T} 2} \\
\vdots & \vdots & \ddots & \vdots \\
\mathrm{p}_{1 \mathrm{~T}} & \mathrm{p}_{2 \mathrm{~T}} & \cdots & \mathrm{p}_{\mathrm{TT}}
\end{array}\right)
$$

Berdasarkan Kim dan Nelson [12], nilai probabilitas smoothed $\left(\operatorname{Pr}\left(S_{t}=i \mid \Psi_{T}\right)\right), t=1,2, \ldots, T, t=1,2, \ldots, T$ dapat dituliskan sebagai berikut,

$$
\operatorname{Pr}\left(\mathrm{S}_{\mathrm{t}}=\mathrm{i} \mid \psi_{\mathrm{T}}\right)=\sum_{\mathrm{s}=1}^{\mathrm{T}} \operatorname{Pr}\left(\mathrm{S}_{\mathrm{t}+1}=\mathrm{s} \mid \psi_{\mathrm{T}}\right) \operatorname{Pr}\left(\mathrm{S}_{\mathrm{t}}=\mathrm{i} \mid \mathrm{S}_{\mathrm{t}+1}=\mathrm{T}, \Psi_{\mathrm{T}}\right)
$$

Berdasarkan Sopipan dkk [13], nilai probabilitas smoothed pada waktu $\mathrm{T}+1$ dapat diprediksi dengan

$$
\operatorname{Pr}\left(S_{t+1}=i \mid \psi_{T}\right)=p_{1 i} P\left(S_{t}=1 \mid \psi_{T}\right)+p_{2 i} P\left(S_{t}=2 \mid \psi_{T}\right)+\cdots+p_{j i} P\left(S_{t}=j \mid \psi_{T}\right) .
$$


Dimana pji menunjukkan elemen-elemen dari matriks transisisi $\mathrm{P}_{\mathrm{j}} \mathrm{x}_{\mathrm{j}}$. Sinyal krisis jangka pendek dapat ditunjukkan dari jumlah nilai prediksi probabilitas smoothed.

\subsection{Langkah Penelitian}

Data bulanan nilai tukar nominal dari Januari 1990 sampai Oktober 2018 diambil dari International Monetary Fund (IMF). Dengan data Januari 1990 sampai Desember 2017 sebagai data training dan data Januari 2018 sampai Oktober 2018 sebagai data testing. Langkah-langkah dalam penelitian ini sebagai berikut.

1. Membuat plot data dan uji kestasioneran menggunakan uji ADF (augmented Dickey Fuller). Apabila data tidak stasioner maka dilakukan transformasi data menggunakan log return.

2. Membuat model ARMA dan melakukan uji diagnostik model terbaik ARMA.

3. Menuji adanya keheterogenan pada variansi (uji heteroskedastisitas) residu ARMA menggunakan uji Lagrange multiplier.

4. Apabila hasil uji Lagrange mutliplier menunjukkan bahwa residu model ARMA mengandung heteroskedastisitas maka dilakukan identifikasi model volatitas. Selanjutnya dilakukan uji diagnostik (uji autokorelasi, heteroskedastisitas dan normalitas).

5. melakukan kombinasi model volatilitas EGARCH dan model Markov regime switching.

6. Hitung nilai probabilitas smoothed dari setiap data nilai tukar nominal.

7. Apabila nilai probabilititas smoothed nilai tukar nominal lebih dari nilai probabilitas smoothed pada periode krisis tahun 1997 maka diprediksi adanya krisis keuangan.

8. Membuat model MS-EGARCH

\section{HASIL DAN PEMBAHASAN}

Plot data nominal exchange rate dapat dilihat pada Gambar 1.

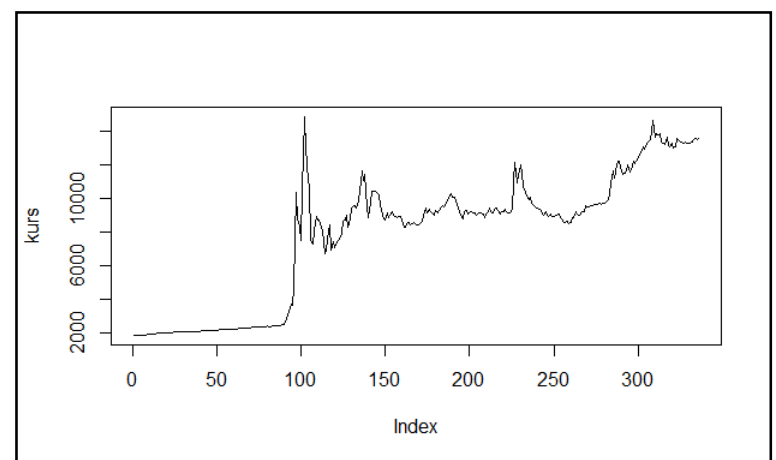

FIGURE 1. Plot indikator nominal exchange rate.

Gambar 1 memuat trend yang mengindikasikan bahwa data tidak stasioner. Selain itu, stasioneritas data dapat juga dilihat dari uji ADF. Berdasarkan uji ADF diperoleh nilai probabilitias lebih besar dari 0.05, yang berarti bahwa data tidak stasioner sehingga diperlukan transformasi log return. Plot transformasi log return nilai tukar nominal dapat dilihat pada Gambar 2.

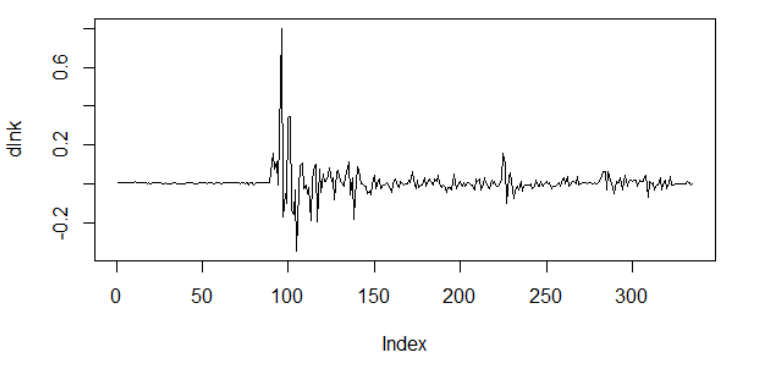

GAMBAR 2. Plot transformation log return untuk nilai tukar nominal. 
Gambar 2 menunjukkan bahwa data log return tidak mengandung trend yang mengindikasikan bahwa data stasioner. Kestasioneran data dapat ditunjukkan oleh uji ADF. Berdasarkan uji ADF diperoleh nilai probabilitas kurang dari 0.05 yang berarti bahwa data sudah stasioner. Setelah data stasioner, dilakukan uji ACF dan PACF untuk menentukan model ARMA yang digunakan. Berdasarkan nilai AIC, diperoleh model terbaik ARMA(2,0). Model ARMA(2,0) ditulis sebagai berikut,

$$
\mathrm{r}_{\mathrm{t}}=0.13847 \mathrm{r}_{\mathrm{t}-1}-0.13140 \mathrm{r}_{\mathrm{t}-2}+\varepsilon_{\mathrm{t}}
$$

Selanjutnya, dilakukan uji heteroskedastisitas dari residu model ARMA(2,0). Berdasarkan uji Lagrange multiplier, diperoleh nilai probabilitas lebih kecil dari 0.05. Hal ini berarti bahwa residu model ARMA mengandung heteroskedastisitas. Untuk menangani heterokedastisitas digunakan model volatilitas GARCH. Model volatilitas untuk nilai tukar nominal adalah $\operatorname{GARCH}(1,1)$, yang dapat ditulis sebagai berikut,

$$
\sigma_{\mathrm{t}}^{2}=0.00002513+1.042 \mathrm{a}_{\mathrm{t}-1}^{2}+0.4165 \sigma_{\mathrm{t}-1}^{2}
$$

$\sigma_{\mathrm{t}}^{2}$ merupakan variansi pada waktu $\mathrm{t}$, dan $\mathrm{a}_{\mathrm{t}}$ merupakan residu pada waktu $\mathrm{t}-1$.

Selanjutnya, dilakukan uji diagnostik dari residu model $\operatorname{GARCH}(1,1)$. Berdasarkan uji Ljung-Box, diperoleh nilai probabilitias lebih besar dari 0.05 , yang berarti bahwa residu model volatilitas tidak mengandung autokorelasi. Dari uji Lagrange multiplier diperoleh nilai probabilitas lebih besar dari 0.05 , yang berarti bahwa residu model volatilitas sudah homogen. Nilai probabilitas dari uji Kolmogorov-Smirnov lebih besar dari 0.05 , yang berarti bahwa residu model volatilitas berdistribusi normal.

Selanjutnya, dilakukan uji Sign bias untuk melihat adanya leverage effect pada residu, berdasarkan output uji sign bias diperoleh probabilitas sign bias sebesar 0.5666064 yang lebih besar dari proabilitas toleransi 0.05 artinya terindikasi adanya efek leverage, untuk mengakomodasi adanya keasimetrikan maka dilanjutkan ke pemodelan EGARCH yang mampu mengatasi leverage effect. Model volatilitas untuk mengatasi keasimetrikan pada residu nilai tukar nominal adalah $\operatorname{EGARCH}(1,1)$ yang dapat ditulis sebagai berikut,

$$
\ln \sigma_{\mathrm{t}}^{2}=-0.378449+0.341294 \ln \left(\sigma_{\mathrm{j}, \mathrm{t}-1}^{2}\right)+\gamma \frac{\varepsilon_{\mathrm{t}-1}}{\sqrt{\sigma_{\mathrm{t}-1}^{2}}}+0.4165\left[\frac{\left|\varepsilon_{\mathrm{t}-1}\right|}{\sqrt{\sigma_{\mathrm{t}-1}^{2}}}-\sqrt{\frac{2}{\pi}}\right]
$$

Regime merupakan perubahan kondisi yang terjadi dalam model Markov regime switching. Regime diasumsikan mengikuti orde pertama rantai markov dengan probabilitas transisi pij dengan $\mathrm{i}, \mathrm{j}=1,2$ untuk indikator real interest rate on deposits dan $\mathrm{i}, \mathrm{j}=1,2,3$ untuk nominal exchange rate. Sehingga, model Markov regime switching exponential generalized autoregressive heteroscedasticity MS-EGARCH $(3,1,1)$ untuk indikator nilai tukar nominal (nominal exchange rate) merupakan model EGARCH(1,1) yang memiliki 3 regime, dengan regime 1,2,3 berurutan menggambarkan volatilitas rendah,sedang, dan tinggi. Suatu regime mempunyai kemungkinan untuk bertahan pada regime yang sama atau pindah ke regime yang lain pada waktu berikutnya. Probabilitas dari perubahan regime dapat dilihat dalam bentuk matriks probabilitas transisi. Matriks probabilitas transisi 3 regime untuk nilai tukar nominal sebagai berikut.

$$
P=\left(\begin{array}{lll}
0.9851 & 0.0001 & 0.0147 \\
0.0178 & 0.9555 & 0.0267 \\
0.0000 & 0.0823 & 0.9177
\end{array}\right)
$$

Untuk mendeteksi krisis, dapat dilihat dari nilai probabilitas smoothed paling rendah pada saat krisis terjadi di Indonesia (Juni 1997 - Januari 1998). Sehingga diperoleh hasil krisis terjadi ketika nilai probabilitias smoothed lebih dari atau sama dengan 0.9755277. Plot nilai probabilitas smoothed nilai tukar nominal dapat dilihat pada Gambar 3. 


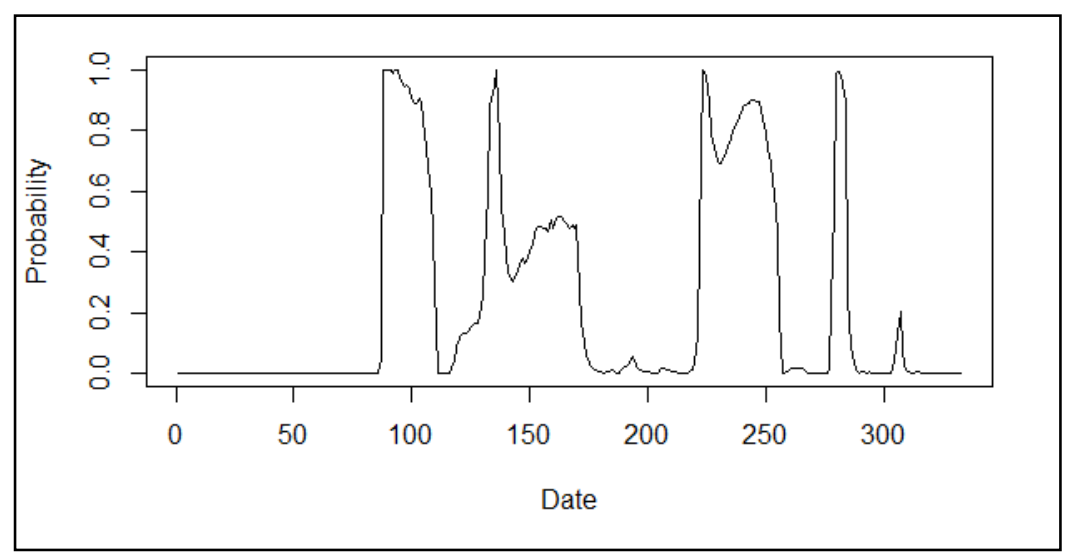

GAMBAR 3. Smoothed probability dari nominal exchange rate.

Gambar 3 menunjukkan menunjukkan terdapat 15 nilai probabilitas smoothed yang lebih besar dari 0.9755277. Indikator nilai tukar nominal mendeteksi krisis pada Juni 1997 - Januari 1998, Juni 2001, September 2008 - November 2008, dan Juni 2013 - Agustus 2013. Sehingga, dapat disimpulkan bahwa model MS-EGARCH $(3,1,1)$ untuk indikator nilai tukar nominal dapat mendeteksi krisis.

Selanjutnya, prediksi nilai probabilitas smoothed dihitung. Hasil perhitungan prediksi nilai probabilitas smoothed periode selanjutnya untuk nominal exchange rate ditunjukkan pada Tabel 1.

TABLE 1. Comparison of smoothed probability predictions dan actual for nominal exchange rate.

\begin{tabular}{lllll}
\hline Period & $\begin{array}{l}\text { Prediction } \\
\text { smoothed probability }\end{array}$ & $\begin{array}{l}\text { Prediction } \\
\text { crisis } \\
\text { condition }\end{array}$ & $\begin{array}{l}\text { Actual } \\
\text { smoothed } \\
\text { probability }\end{array}$ & $\begin{array}{l}\text { of } \\
\text { Actual crisis } \\
\text { condition }\end{array}$ \\
\hline January 2018 & 0.0400 & stable & 0.201 & stable \\
February 2018 & 0.0507 & stable & 0.201 & stable \\
March 2018 & 0.0604 & stable & 0.201 & stable \\
April 218 & 0.0690 & stable & 0.201 & stable \\
May 2018 & 0.0768 & stable & 0.201 & stable \\
June 2018 & 0.0837 & stable & 0.201 & stable \\
July 2018 & 0.0898 & stable & 0.200 & stable \\
August 2018 & 0.0953 & stable & 0.200 & stable \\
September 2018 & 0.100 & stable & 0.200 & stable \\
October 2018 & 0.104 & stable & 0.200 & stable \\
\hline
\end{tabular}

Berdasarkan Tabel 1, dapat disimpulkan bahwa kondisi krisis aktual dan prediksi sama. Ini berarti, model tersebut cukup baik digunakan untuk mendeteksi krisis berdasarkan indikator nilai tukar nominal.

\section{KESIMPULAN}

Model gabungan Markov Switching dan Exponential generalized conditional heteroskedasticity, MSEGARCH $(3,1,1)$ cukup baik dalam mendeteksi periode krisis yang terjadi di Indonesia berdasarkan indikator nilai tukar nominal.

\section{REFERENSI}

[1] Engle RF, Econometrics 50987 (1982).

[2] Bollerslev T, Journal of Econometrics 31307 (1986).

[3] Chen MY, "Markov Switching Models," (Department of Finance National Chung Hsing University, 2008)

[4] Nelson DB, Econometrica 59347 (1991).

[5] Hamilton JD, Econometrics 57357 (1989). 
[6] Hamilton JD dan Susmel R, J. of Econometrics 64307 (1994).

[7] Chang K, Cho KY dan Hong M, Journal. of Econonomic Research 5249 (2010).

[8] Sugiyanto, Etik Z dan Meganisa S, Journal of Phys.: Conf. Series 1025 012115(2018).

[9] Sugiyanto, Etik Z dan Shania P S, Journal of Phys.: Conf. Series 1025012118 (2018).

[10] Tsay, R.S, “Analysis of Financial Time Series," (John Wiley dan Sons, Canada, 2005).

[11] Gray, S.F., "Modeling the Conditional Distribution of Interest Rates as A Regime-Switching Process," Journal of Finance Economics 42, 27-62 (1996).

[12] Kim, C.J. dan Nelson, C.R. "State-Space Models with Regime Switching: Classical dan GibbsSampling Approaches with Application," (The MIT Press, London, 1999).

[13] Sopipan, N., Sattayatham P., dan Premanode B., "Forecasting Volatility of Gold Price Using Markov Regime Switching dan Trading Strategy," Journal of Mathematical Finance, 2, 121-131 (2012). 